\title{
Hyponatremia in Children with Pneumonia: Study in a Tertiary Care Hospital, Dinajpur, Bangladesh
}

\author{
Dr. Sk. Sadek Ali ${ }^{1 *}$, Dr. Mohammad Kamruzzaman ${ }^{1}$, Dr. Mostafa Zaman ${ }^{1}$, Dr. Shah Md. Moazzem Hossain ${ }^{2}$, Dr. Mst.
} Halima Sarker ${ }^{3}$

${ }^{1}$ Assistant Professor, Department of Paediatrics, M Abdur Rahim Medical College, Dinajpur, Bangladesh

${ }^{2}$ Senior Consultant, Department of Paediatrics, M Abdur Rahim Medical College, Dinajpur, Bangladesh

${ }^{3} \mathrm{IMO}$, Paediatrics, M Abdur Rahim Medical College, Dinajpur, Bangladesh

DOI: $10.36347 /$ sjams.2020.v08i08.030

| Received: 16.07 .2020 | Accepted: 24.07.2020 | Published: 30.08.2020

*Corresponding author: Dr. Sk. Sadek Ali

Abstract

Original Research Article

Pneumonia is an infection in the lungs. It can cause breathing problems, a fever, coughing and wheezing. Pneumonia can affect people of any age, but babies and young children are at higher risk because their immune systems are not yet fully developed. Hence the current study was planned to evaluate the prevalence of the pneumonia in children and assess the level of serum sodium in affected children. The aim of our study was to assess the Serum sodium levels in children in pneumonia and the scenario of pneumonia in children in Bangladesh. The study was planned in the department of Pediatrics, the department of paediatrics, M Abdur Rahim Medical College, Dinajpur, Bangladesh during the period from January 2018 To December 2018. One hundred and twenty five (125) study subjects were selected purposively. At the time of admission, the patient's clinical history was recorded in prefixed preform. Venous blood sampling was obtained from each patient enrolled in the study and sent for estimation of serum electrolytes, glucose levels, X-Ray Chest. Data were analyzed by using SPSS version 21. The highest Serum Sodium level for Pneumonia $((\mathrm{mEq} / \mathrm{L}))$ in $(131-135)$ range was $100(40 \%)$, higher (135-140) range was 85(34\%), high (126-130) range was $60(24 \%)$ and lowest (120-125) range was 5(2\%). Hyponatremia is quite common in community acquired pneumonia cases that needed hospitalization. Initial measurement of serum sodium is recommended in all hospitalized pneumonia patients. Regular follow up of serum sodium level during the period of hospital stay should be considered to pick up the high risk cases at an early stage. Based on the above findings it can be concluded that regular estimation of serum electrolyte concentration and $30 \%$ has been curtailed from the regular daily intake fluid volume to guide appropriate fluid and electrolyte management of children with severe pneumonia requiring hospitalization.

Keywords: Pneumonia, Sodium level, Hyponatremia.

Copyright @ 2020: This is an open-access article distributed under the terms of the Creative Commons Attribution license which permits unrestricted use, distribution, and reproduction in any medium for non-commercial use (NonCommercial, or CC-BY-NC) provided the original author and source are credited.

\section{INTRODUCTION}

Pneumonia is an infection in the lungs. It can cause breathing problems, a fever, coughing and wheezing. Pneumonia can affect people of any age, but babies and young children are at higher risk because their immune systems are not yet fully developed. Hence the current study was planned to evaluate the prevalence of the pneumonia in children and assess the level of serum sodium in affected children. The World Health Organization estimates that more than 160 million children around the world develop pneumonia each year, 20 million of whom are hospitalized and 2 million of whom die. Worldwide, pneumonia is the leading cause of death for children under the age of five. Sub-Saharan Africa is disproportionately affected, accounting for more than half of such cases. In developed countries, access to antibiotics and vaccines has mostly controlled incidents of childhood pneumonia. However, in developing countries, pneumonia takes the lives of more children than any other single cause each year, including any other single disease, war, or famine. Despite this terrible reality, programs to fight childhood pneumonia remain critically underfunded, with large amounts of resources being devoted to HIV/AIDS and malaria. Estimates show that 1.3 million of childhood pneumonia deaths could be avoided if prevention and treatment efforts were implemented worldwide. After the germs reach the lungs, the lungs become inflamed and fill up with fluid. This causes breathing difficulties, which makes it difficult for enough oxygen to enter the bloodstream. The body's cells can't function as they normally would, and infection can't be flushed from the body. If untreated, the infection may continue to spread, leading to death. In 2008, pneumonia occurred in approximately 
156 million children (151 million in the developing world and 5 million in the developed world). In 2010, it resulted in 1.3 million deaths, or $18 \%$ of all deaths in those under five years, of which $95 \%$ occurred in the developing world. Countries with the greatest burden of disease include India (43 million), China (21 million) and Pakistan (10 million). It is the leading cause of death among children in low income countries [1]. Many of these deaths occur in the newborn period. The World Health Organization estimates that one in three newborn infant deaths is due to pneumonia. Approximately half of these deaths can be prevented, as they are caused by the bacteria for which an effective vaccine is available. In 2011, pneumonia was the most common reason for admission to the hospital after an emergency department visit in the U.S. for infants and children [2]. Bacteria, viruses, or fungi that live in your nose, mouth, sinuses, or the surrounding environment can enter your lungs and create infections, including pneumonia. You can get the bacteria or viruses from people who are infected with them, whether they show symptoms or not. The leading cause of severe pneumonia in children in developing countries is Streptococcus pneumoniae bacteria or pneumococcus. Another leading cause is Haemophilus influenzae type $b$ or Hib. Other causes of pneumonia include influenza, staph infections, human respiratory syncytial virus, rhinovirus, herpes simplex virus, and severe acute respiratory syndrome (SARS). Less common types of pneumonia can be acquired. Through the inhalation of food, liquids, gases, dust, and certain fungi. Pneumocystis carinii (now renamed Pneumocystis jiroveci) pneumonia (PCP) is a fungal infection that can affect people with weakened immune systems, including those with HIV/AIDS. Practicing good hygiene and health habits help prevent pneumonia. Thorough and frequent hand cleaning, coughing or sneezing into an elbow or sleeve instead of hands, avoiding interaction with those who are sick, receiving proper nutrition, and getting adequate rest are all things you and your children can do to ward off the bacteria and viruses that can cause pneumonia. Avoiding tobacco smoke and other pollutants help prevent pneumonia. Increasing access to immunization, reducing indoor and outdoor air pollution, and becoming knowledgeable about warning signs to identify infection, specifically a cough, fast breathing, and/or difficulty breathing will help prevent infection. Breastfeeding during the first six months is critical in preventing pneumonia. Breast milk contains ample supply of nutrients, antioxidants, hormones and antibodies needed for growth and development of a child. The literature findings suggest that the lower respiratory infections (LRIs), pneumonia, atypical pneumonia, bronchitis, bronchiolitis, and severe acute respiratory syndrome (SARS), continue to threaten the health of children worldwide and especially in developing countries, where poor nutrition prevails and access to health care are scarce. Hence the current study was planned to evaluate the prevalence of the pneumonia in the children's and assess the levels of serum sodium in affected children's.

\section{OBJeCTIVES \\ General Objective}

- To assess hyponatremia in children with pneumonia.

\section{Specific Objectives}

- To observe the scenario of pneumonia in children in Bangladesh.

\section{Materials \& Methods}

The present study was planned on 125 children diagnosed with pneumonia in the department of Pediatrics, the department of paediatrics, M Abdur Rahim Medical College, Dinajpur, Bangladesh during the period from January 2018 To December 2018. At the time of admission, the patient's clinical history was recorded in prefixed proforma. Venous blood sampling was obtained from each patient enrolled in the study and sent for estimation of serum electrolytes, glucose levels, X-Ray Chest. Normal values of serum sodium ranges from 136-145 m mol/L or mEq/L. Hyponatremia is usually defined as a serum sodium concentration of less than $135 \mathrm{mEq} / \mathrm{L} 3$. Following was the inclusion and exclusion criteria of the present study. A pre-designed questioner had been used to collect all the necessary data from the participants. Program MS-Excel was used in collecting data, SPSS version 21 was used in analyzing data. On the other hand several tables were used to disseminate data.

\section{Inclusion Criteria}

- Children with pneumonia between 1-6 years of age.

\section{Exclusion Criteria}

- Children with severe malnutrition, Diarrhea, Congestive heart failure, Meningitis, Nephrotic syndrome and Acute Glomerular Nephritis.

\section{RESULTS}

The data from the 125 children diagnosed with the pneumonia were collected and discussed as follows. In (Table-1) we showed that the Distribution of Study Subjects According To Age Group the majority age group (1-2 years) was $210(84 \%)$ then age group (2-4 years) $25(10 \%)$ and lowest age group (4-6 years) was $15(6 \%)$. In (Table-2) the highest acute respiratory infection Severe Pneumonia was found 160(64\%), high Pneumonia was $80(32 \%)$ and lowest one Very Severe Pneumonia was $10(4 \%)$. Distribution of study subjects according to frequency of hyponatremia in (Table-3) the severity of pneumonia there are two groups (groups-I, group-II) with hyponatremia100(40\%)Where Severe Pneumonia was found 65(26\%), Pneumonia was $25(10 \%)$ and Very Severe Pneumonia was $10(4 \%)$. In 
(group-II) with hyponatremia150 (40\%) Where Severe Pneumonia was found $90(36 \%)$, Pneumonia was $45(18 \%)$ and Very Severe Pneumonia was $15(6 \%)$. Distribution of pneumonia cases by their range of serum sodium in (Table-4) the highest Serum Sodium
Pneumonia $((\mathrm{mEq} / \mathrm{L}))$ in $(131-135)$ range was $100(40 \%)$, higher (135-140) range was $85(34 \%)$, high (126-130) range was 60(24\%) and lowest (120-125) range was $5(2 \%)$.

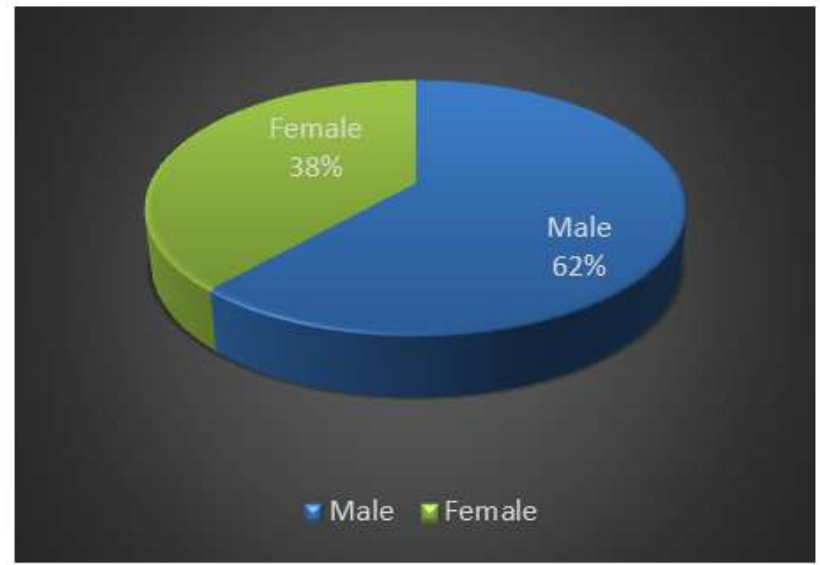

Fig-1: Gender distribution of Participants ( $=125)$

Table-1: Distribution of Study Subjects According To Age Group (N=125)

\begin{tabular}{|l|l|l|}
\hline \multirow{2}{*}{ Age group (in years) } & \multicolumn{2}{|l|}{ No. of Cases(N=125) } \\
\cline { 2 - 3 } & $\mathbf{N}$ & $\mathbf{\%}$ \\
\hline $1-2$ & 105 & 84 \\
\hline $2-4$ & 13 & 10.4 \\
\hline $4-6$ & 7 & 5.6 \\
\hline Total & 250 & 100 \\
\hline
\end{tabular}

Table-2: Distribution of study subjects according to who classification of acute respiratory infections $(\mathrm{N}=250)$

\begin{tabular}{|l|l|l|}
\hline \multirow{2}{*}{ Classification } & No. of Cases $(\mathbf{N}=\mathbf{1 2 5})$ \\
\cline { 2 - 3 } & $\mathbf{N}$ & $\mathbf{\%}$ \\
\hline Pneumonia & 40 & 32 \\
\hline Severe Pneumonia & 80 & 64 \\
\hline Very Severe Pneumonia & 5 & 4 \\
\hline Total & 125 & 100 \\
\hline
\end{tabular}

Table-3: Distribution of study subjects according to frequency of hyponatremia $(\mathrm{N}=125)$

\begin{tabular}{|l|l|l|l|l|}
\hline \multirow{2}{*}{ Severity of pneumonia } & \multicolumn{2}{|l|}{ With (group-1) hyponatremia } & \multicolumn{2}{l|}{ Without(group-2) hyponatremia } \\
\cline { 2 - 5 } & $\mathbf{N}$ & $\mathbf{\%}$ & $\mathbf{N}$ & \% \\
\hline Pneumonia & 13 & 10.4 & 22 & 17.6 \\
\hline Severe Pneumonia & 33 & 26.4 & 46 & 36.8 \\
\hline Very Severe Pneumonia & 4 & 3.2 & 7 & 5.6 \\
\hline Total & 50 & 40 & 75 & 60 \\
\hline
\end{tabular}

\section{DISCUSSION}

Hyponatremia is the most common serum electrolyte abnormality. The etiology of hyponatremia in the critically ill child may reflect an endogenous state of sodium deregulation, iatrogenic causes, or both. Children admitted to the critical care study lies in the fact that this is the only study in pediatric age group where correlation of hospital-acquired and hospitalaggravated hyponatremia with morbidity and mortality in hospitalized pneumonia patients is sought for. Few studies exist concerning the correlation of hyponatremia and pneumonia in children. It was first described by
Stormont and Waterhouse in 1962 [3]. Since then and during the past 35 years, only case reports and a few relevant studies on the association between hyponatremia and pneumonia have been published, of which only three concern children $[4,5]$. Communityacquired (CAP) and nosocomial pneumonias contribute substantially to morbidity and hospital resource utilization [6, 7]. Hyponatraemia, occurring in more than $1 / 4$ of patients with CAP, is associated with greater disease severity and worsened outcomes. Hyponatraemia is usually mild in children with CAP [8]. It seems that high atrial natriuretic peptide levels (ANP) may play a role [9]. Atrial natriuretic peptide is a 
member of the family of natriuretic peptides, and regulates a variety of physiological parameters, such as diuresis and natriuresis, and reduces systemic blood pressure. It is synthesized and secreted from cardiac atria. Increased levels of ANP were found in diseases affecting the lungs. Over- secretion of ANP is correlated with hypoxia, which leads to pulmonary vasoconstriction, pulmonary hypertension, and rightheart overload [10, 11]. Hyponatremia occurring in children with pneumonia comprises part of the syndrome of inappropriate antidiüretic hormone secretion (SIADH). ADH is generally secreted by the pituitary gland in response to high plasma osmolality (high serum sodium concentration); however, in various clinical conditions, including fever, hypoxia, hypercarbia, pain, nausea, and vomiting, nonosmotic stimulation of $\mathrm{ADH}$ secretion can lead to hyponatremia. Also, the stimulus of ADH release in pulmonary disease is likely to be nonosmotic; in particular, lung hyperinflation and pulmonary infiltrates may stimulate $\mathrm{ADH}$ secretion by causing a false perception of hypovolemia by intrathoracic receptors [12].

\section{LMitation OF THE STUdy}

This was a single centered observatory study with a small sample size. So the findings of this study may not reflect the exact scenarios of whole country.

\section{CONCLUSION AND}

\section{RECOMMENDATIONS}

Hyponatremia is quite common in community acquired pneumonia cases needed hospitalization. Initial measurement of serum sodium is recommended in all hospitalized pneumonia patients. Regular follow up of serum sodium level during the period of hospital stay should be considered to pick up the high risk cases at an early stage. Based on the above findings it can be concluded that regular estimation of serum electrolyte concentration is necessary to guide appropriate fluid and electrolyte management of children with severe pneumonia hospitalization.

\section{REFERENCES}

1. Ruuskanen O, Lahti E, Jennings LC, Murdoch DR. Viral pneumonia. Lancet. 377(9773): 1264-75.

2. Weiss AJ, Wier LM, Stocks C, Blanchard J. Overview of Emergency Department Visits in the United States, 2011. HCUP Statistical Brief \#174. Rockville, MD: Agency for Healthcare Research and Quality. Archived from the original on, 2014.

3. Stormont JM, Waterhouse C. Severe hyponatraemia associated with pneumonia. Metabolism. 1962; 11:1181-6.

4. 1hann F, Germer S. Hyponatraemia associated with pneumonia or bacterial meningitis. Arch Dis Child. 1985; 60:963-6.

5. Nair V, Niederman MS, Masani F, Fishbane S. Hyponatremia in community-acquired pneumonia. Am J Nephrol. 2007; 27:184-190.

6. Zilberberg MD, Exuzides A, Spalding J, Foreman A, Jones AG, Colby C, Shorr AF. Hyponatremia and hospital outcomes among patients with pneumonia: a retrospective cohort study. BMC pulmonary medicine. 2008 Dec 1;8(1):16.

7. Jabłoński S, Modrzewski W, Rysz J, Machała W, Jabłonowski Z, Kordiak J. Pulmonary abscesses aetiology and treatment. Ten-year experience of the Department of General and Thoracic Surgery in Lodz, Poland. Arch Med Sci. 2006; 2:47-54.

8. Don M, Valerio G, Korppi M, Canciani M. Hyponatremia in pediatric community-acquired pneumonia. Pediatr Nephrol. 2008; 23:2247-53.

9. Haviv M, Haver E, Lichtstein D, Hurvitz H, Klar A. Atrial natriuretic peptide in children with pneumonia. Pediatr Pulmonol. 2005; 40:306-9.

10. Yap LB, Mukerjee D, Timms PM, Ashrafian H, Coghlan JG. Natriuretic peptides, respiratory disease, and the right heart. Chest. 2004; 126:1330-6.

11. Wilkins MR, Redondo J, Brown LA. The natriuretic-peptide family. Lancet. 1997; 349:1307-10.

12. Gozal D, Colin AA, Jaffe M, Hochberg Z. Water, electrolyte, and endocrine homeostasis in infants with bronchiolitis. Pediatr Res. 1990; 27(2):204-9. 